\title{
(6) OPEN ACCESS \\ Clinical characteristics and treatment of 22 eyes of morning glory syndrome associated with persistent hyperplastic primary vitreous
}

\author{
Ping Fei, Qi Zhang, Jing Li, Peiquan Zhao
}

\begin{abstract}
- Additional material is published online only. To view please visit the journal online (http://dx.doi.org/10.1136/ bjophthalmol-2013-303565).

Department of Ophthalmology, Xinhua Hospital, affiliated to Shanghai Jiaotong University School of Medicine, Shanghai, China
\end{abstract}

\section{Correspondence to}

Dr Peiquan Zhao, Department of Ophthalmology, Xinhua Hospital, affiliated to Shanghai Jiaotong University School of Medicine, No. 1665 , Kongjiang Road, Shanghai 200092, China;

zhaopeiquan@126.com

Received 17 April 2013 Revised 9 June 2013 Accepted 3 July 2013 Published Online First 22 July 2013

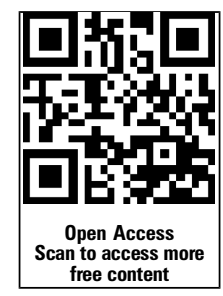

To cite: Fei $P$, Zhang $Q$, Li J, et al. Br J Ophthalmol 2013;97:1262-1267.

\begin{abstract}
Purpose To describe the clinical manifestations and treatment outcomes in a retrospective case series of morning glory syndrome (MGS) associated with persistent hyperplastic primary vitreous (PHPV).
\end{abstract} Methods The medical records of 85 eyes/74 patients referred for ophthalmology consultation diagnosed as MGS in our clinic were reviewed retrospectively. All patients underwent thorough ophthalmological examinations. 22 eyes of 19 patients diagnosed as having MGS associated with PHPV were included, accounting for $25.88 \%$ of all the MGS eyes. Clinical manifestations and management of these patients were documented.

Results 15 patients $(78.95 \%)$ were younger than 1 year old at the first diagnosis. Six eyes were associated with microphthalmia. 19 of 22 eyes $(86.36 \%)$ had complications, including cataract (10 eyes), secondary glaucoma (8 eyes), corneal leucoma or oedema (8 eyes), retinal detachment (8 eyes), strabismus (3 eyes) and nystagmus ( 2 eyes). Treatment methods varied depending on the severity of the complications. Nine eyes with secondary glaucoma or cataract got lensectomy; three eyes underwent combined vitrectomy and lensectomy. Eight patients underwent cranial MRI/ MR angiography or CT examination. Widened cerebral fissures of bilateral temporal lobes, abnormal dilated branch of middle cerebral artery in the left hemisphere and abnormal signal in the grey matter of frontal and occipital lobes were revealed respectively in three patients.

Conclusions Our study revealed the coexistence of PHPV in a significant percentage of patients with MGS, suggesting a potential common genetic link. Compared with MGS and PHPV alone, the combination of the two conditions manifested with higher incidence and more severe complications in younger patients. Close follow-up was recommended. Lensectomy and vitrectomy were beneficial in the management of the complications.

\section{INTRODUCTION}

The morning glory syndrome (MGS) or morning glory disc anomaly was named by Kindler in 1970 because of its resemblance to the morning glory flower. ${ }^{1}$ It is a congenital, funnel-shaped excavation of the posterior fundus that incorporates the optic disc, with a white tuft of glial tissue overlying the central portion of the disc and the increased number of blood vessels arising from the periphery of the disc. Persistent hyperplastic primary vitreous (PHPV) or persistent fetal vasculature is a condition that presents during infancy. It occurs because of a failure of the primary vitreous and the hyaloid vascular system to regress. PHPV typically manifests as unilateral, but rarely bilateral, persistence of the hyaloid system in Cloquet's canal. It is usually associated with microphthalmia, cataract, retinal traction or dysplasia, and elongation of the ciliary processes. $^{23}$

Previous reports showed that MGS could be associated with congenital ocular anomalies in the same and in the fellow eye, including congenital cataract, lid haemangioma, preretinal gliosis, lenticonus, microphthalmia, and non-ocular malformations such as midline craniofacial defects and intracranial vascular anomalies. ${ }^{1}$ 4-13 Individual cases of MGS associated with PHPV have also been reported. ${ }^{14-17}$ However, no previous studies have reported a series of such an association and the prevalence of MGS associated with PHPV is unknown. In this study, we retrospectively reviewed all 85 MGS cases diagnosed in the Department of Ophthalmology, Xinhua Hospital, Shanghai, China from November 2009 to November 2012. We identified 22 cases of MGS associated with PHPV. The clinical presentation and the treatment options were discussed.

\section{METHODS}

This is a retrospective study. Medical records of 85 eyes from 74 patients diagnosed as MGS in our clinic between November 2009 and November 2012 were reviewed. Among them, 22 eyes of 19 patients diagnosed with or followed for MGS associated with PHPV were included in this study. The study was approved by the Ethics Committee of Xinhua Hospital.

Clinical information, including age, sex, laterality, the first noticeable symptoms, family and birth history, systemic and other ocular anomalies was

Table 1 Summary of patients' information

\begin{tabular}{lc}
\hline Variable $(\mathrm{N}=19)$ & Patients, $\mathbf{n}(\%)$ \\
\hline Gender & \\
$\quad$ Male patients & $11(57.89 \%)$ \\
$\quad$ Female patients & $8(42.11 \%)$ \\
Age at diagnosis & \\
$\quad$ Mean age \pm SD (range) & $2.05 \pm 2.92$ years (1 month-14 years) \\
$\leq 1$ year & $15(78.95 \%)$ \\
$1 \sim 10$ years & $3(15.79 \%)$ \\
$\geq 10$ years & $1(5.26 \%)$ \\
Eye & \\
Bilateral & $3(15.79 \%)$ \\
Unilateral & $16(84.21 \%)$ \\
\hline
\end{tabular}


Table 2 Clinical characteristics of patients with MGS associated with PHPV

\begin{tabular}{|c|c|c|c|c|c|c|c|c|c|}
\hline Eye & Patient & Gender & $\begin{array}{l}\text { GA } \\
\text { (weeks) }\end{array}$ & BW (g) & $\begin{array}{l}\text { Age at presentation } \\
\text { (months) }\end{array}$ & $\begin{array}{l}\text { Follow-up } \\
\text { (months) }\end{array}$ & Eye & Diagnosis & Reason for referral \\
\hline 1 & 1 & M & 39 & 3700 & 46 & 23 & $\mathrm{OD}$ & MGS+anterior PHPV & Leucocoria \\
\hline 2 & 2 & M & 40 & 3300 & 3 & 29 & $\mathrm{OD}$ & MGS+PHPV & Corneal leucoma \\
\hline 3 & & & & & 3 & 29 & OS & MGS+PHPV & Leucocoria \\
\hline 4 & 3 & $\mathrm{~F}$ & 36 & 2200 & 8 & 24 & $\mathrm{OD}$ & MGS+PHPV & Leucocoria \\
\hline 5 & 4 & M & 40 & 3600 & 162 & 13 & OS & MGS+PHPV & Poor vision \\
\hline 6 & 5 & M & 39 & 3500 & 2 & 25 & $\mathrm{OD}$ & MGS+PHPV & Corneal leucoma \\
\hline 7 & 6 & $\mathrm{~F}$ & 39 & 3250 & 0 & 20 & OS & MGS+PHPV & Leucocoria \\
\hline 8 & 7 & $\mathrm{~F}$ & 40 & 3650 & 1 & 12 & $\mathrm{OD}$ & MGS+PHPV & Leucocoria \\
\hline 9 & 8 & M & 40 & 3800 & 43 & 20 & OS & MGS+PHPV & Strabismus \\
\hline 10 & 9 & M & 40 & 2500 & 11 & 40 & $\mathrm{OD}$ & MGS+PHPV & Nystagmus \\
\hline 11 & & & & & 11 & 40 & OS & MGS+PHPV & Strabismus, nystagmus \\
\hline 12 & 10 & $\mathrm{~F}$ & 40 & 3230 & 1 & 13 & $\mathrm{OD}$ & MGS+PHPV & Strabismus \\
\hline 13 & 11 & M & 36 & 3250 & 51 & 38 & OS & MGS+PHPV & Corneal leucoma \\
\hline 14 & 12 & $\mathrm{~F}$ & 40 & 3150 & 11 & 18 & $\mathrm{OD}$ & MGS+PHPV & Leucocoria \\
\hline 15 & & & & & 11 & 18 & OS & MGS+PHPV & Leucocoria \\
\hline 16 & 13 & $\mathrm{~F}$ & 40 & 3300 & 10 & 20 & $\mathrm{OD}$ & MGS+PHPV, MGS(fellow eye) & Poor vision \\
\hline 17 & 14 & M & 40 & 3200 & 2 & 13 & OS & MGS+PHPV+microphthalmia & Microphthalmia, leucocoria \\
\hline 18 & 15 & M & 41 & 3500 & 6 & 4 & OS & MGS+PHPV+microphthalmia & Microphthalmia \\
\hline 19 & 16 & M & 39 & 3000 & 11 & 29 & $\mathrm{OD}$ & MGS+PHPV+microphthalmia & Microphthalmia \\
\hline 20 & 17 & $\mathrm{~F}$ & 40 & 3500 & 8 & 20 & OS & MGS+PHPV+microphthalmia & Microphthalmia \\
\hline 21 & 18 & $\mathrm{~F}$ & 40 & 3650 & 1 & 9 & OS & MGS+PHPV+microphthalmia & Microphthalmia \\
\hline 22 & 19 & M & 40 & 3500 & 5 & 24 & OS & $\begin{array}{l}\text { MGS+PHPV+microphthalmia, MGS (fellow } \\
\text { eye) }\end{array}$ & Microphthalmia \\
\hline
\end{tabular}

BW, birth weight; $F$, female; $G A$, gestational age; $M$, male; MGS, morning glory syndrome; OD, right eye; $O S$, left eye; PHPV, persistent hyperplastic primary vitreous.

investigated. As per routine, all patients underwent comprehensive examinations, including indirect ophthalmoscope examination and wide-angle retina photography using RetCam (Clarity Medical Systems, Pleasanton, California, USA) for young patients or fundus photography using cSLO-HRA2 (Heidelberg Engineering, Dossenheim, Germany) for adult patients. For those whose fundus was invisible at the first referral, due to the corneal opacity or leucocoria, ultrasound examination was performed. Typically MGS associated with PHPV would appear as an excavated optic head with a cord rising from the optic head to the posterior pole of the lens. In some cases, further diagnosis was confirmed during surgery. Microphthalmia was diagnosed if the axial length of the eye was less than at least 2 SDs below the mean for the age of the patient. ${ }^{18}{ }^{19}$ All patients were recommended to have cranial MRI and MR angiography (MRA) or CT. However, only eight patients underwent examinations due to financial constraints.

Lensectomy and/or vitrectomy were performed in patients with complications of glaucoma, cataract and retinal detachment by the same retinal surgeon (PZ). Those who were unlikely to benefit from surgery were subjected to close follow-up and given medications if needed. Patients without any complications or those with only strabismus and/or nystagmus were left untreated.

\section{RESULTS}

\section{Patient information and clinical presentations}

In our study, 22 eyes of 19 patients were diagnosed as MGS associated with PHPV, accounting for $25.88 \%$ of all the MGS eyes, including 11 young boys and 8 young girls. All the patients were born at full term or late preterm, with birth weight above $2500 \mathrm{~g}$ (average 3304.21 $\pm 400.49 \mathrm{~g}$ ). Patient information is summarised in table 1 . None of the patients had a positive related family history. The median and mean lengths of follow-up were 20 and 21.86 months, respectively (range 4-40 months).

Three patients had bilateral MGS associated with PHPV. The remaining 16 patients had unilateral association of MGS and PHPV, and two of them were also diagnosed as having MGS in the fellow eye. Six eyes were also associated with
Figure 1 One patient with morning glory syndrome (MGS) associated with persistent hyperplastic primary vitreous (PHPV). (A) The typical MGS optic; (B) PHPV with prolonged ciliary process.
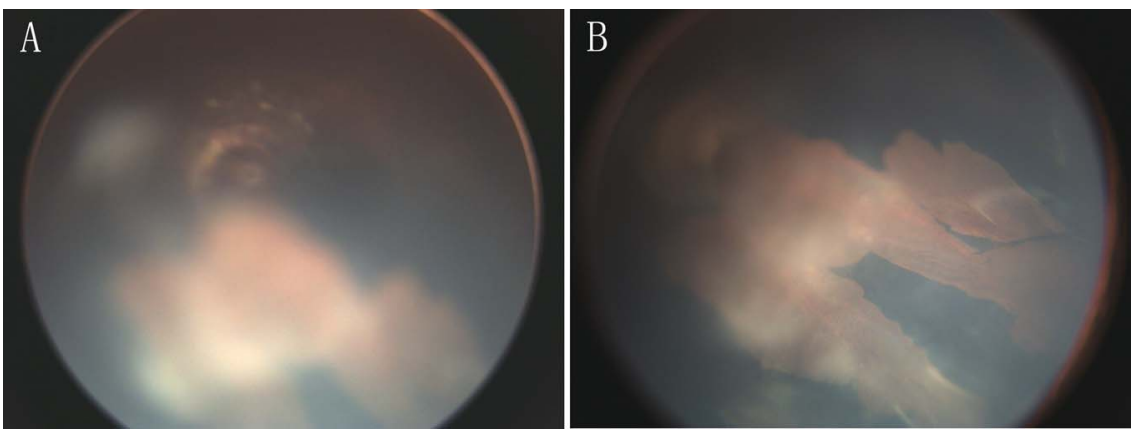
Figure 2 (A) Leucocoria; (B) fundus of morning glory syndrome associated with persistent hyperplastic primary vitreous.
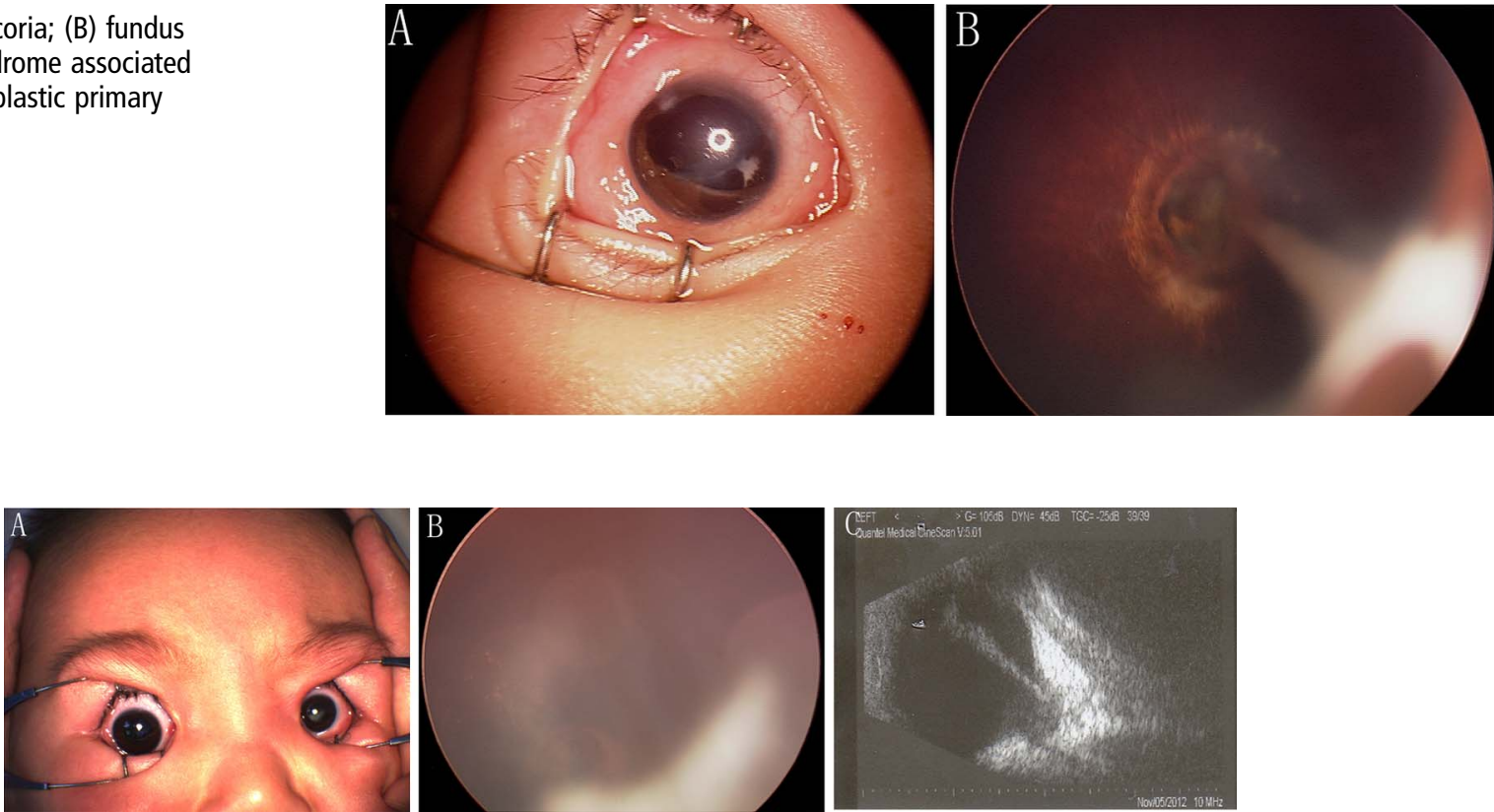

Figure 3 Patient with morning glory syndrome associated with persistent hyperplastic primary vitreous and microphthalmia of left eye.

(A) Microphthalmia; (B) fundus; (C) typical ultrasound scan shows the excavated optic head and a cord rising from the optic head to the posterior pole of the lens.

microphthalmia. Only one eye manifested as anterior PHPV (tables 1 and 2, figures 1-3)

The first clinical manifestation noticed by parents was leucocoria in 8 eyes (including one eye that had both microphthalmia and leucocoria), microphthalmia in 6 eyes, corneal leucoma in 3 eyes, strabismus in 3 eyes, poor vision in 2 eyes, nystagmus in 2 eyes (including one that presented with both nystagmus and strabismus) (table 2).

Nineteen of the 22 eyes $(86.36 \%)$ had complications including cataract, secondary glaucoma, corneal leucoma or oedema, retinal detachment, strabismus and nystagmus (summarised in table 3). Visual acuity was difficult to evaluate in preverbal patients and the data were incomplete.

Among eight patients with cranial MRI/MRA or CT results, three showed abnormalities. One patient showed widened cerebral fissures of the bilateral temporal lobes; one showed an abnormal dilated branch of the middle cerebral artery in the left hemisphere (figure 4); the other patient showed an abnormal signal in the grey matter of the frontal and occipital lobes.

\section{Treatment and outcomes}

The treatment and outcome of individual patients are listed in table 4 . The age of all patients who had surgery ranged from

\section{Table 3 Summary of complications}

\begin{tabular}{ll}
\hline Complications & Number of eyes \\
\hline Cataract & 10 \\
Secondary glaucoma & 8 \\
Corneal leucoma/oedema & 8 \\
Retinal detachment & 8 \\
Strabismus & 3 \\
Nystagmus & 2 \\
No complications & 3 \\
\hline
\end{tabular}

1 month to 5 years (median and average age were 3 months and 13.25 months, respectively).

We performed lensectomy in nine eyes to remove cataract, or to prevent corneal opacity in eyes with secondary glaucoma and shallow anterior chamber. Two of the nine eyes received secondary surgery of coreplasty 5 and 20 months after lensectomy, respectively, when the fibrous pupillary membrane was observed.

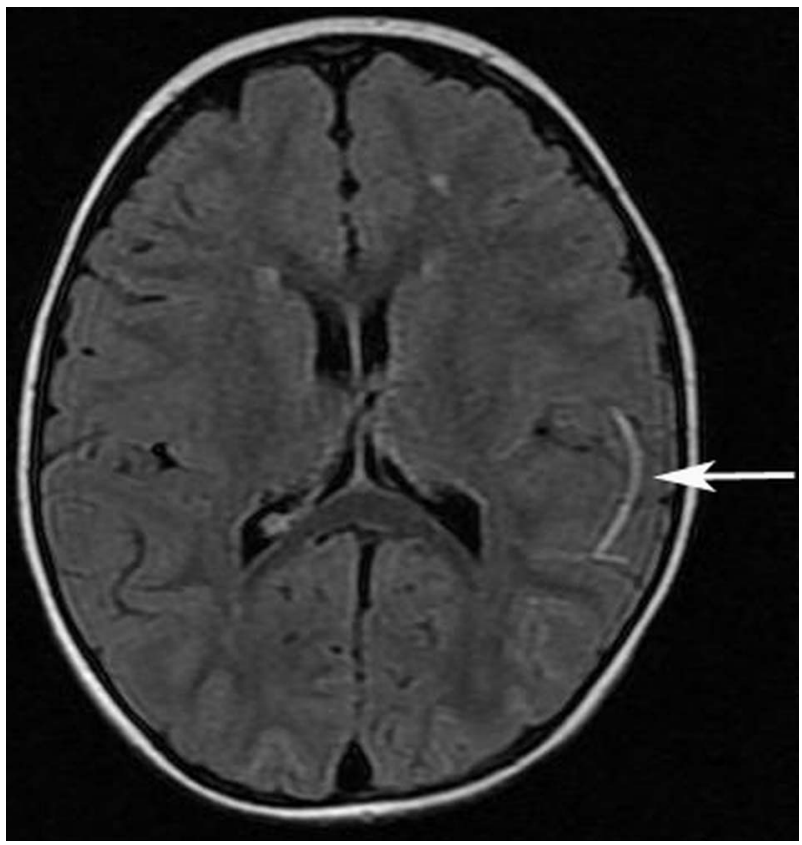

Figure 4 MRI reveals an abnormal dilated branch of the middle cerebral artery in the left hemisphere in a patient with morning glory syndrome associated with persistent hyperplastic primary vitreous (arrow). 
Table 4 Complications and treatment of patients with MGS complicated with PHPV

\begin{tabular}{|c|c|c|c|c|c|c|c|c|c|c|c|c|c|c|c|}
\hline \multirow[b]{2}{*}{ Eye } & \multirow[b]{2}{*}{ Patient } & \multirow[b]{2}{*}{ Eye } & \multirow[b]{2}{*}{ Diagnosis } & \multirow[b]{2}{*}{ Treatment } & \multicolumn{2}{|c|}{$\begin{array}{l}\text { Secondary } \\
\text { glaucoma }\end{array}$} & \multicolumn{2}{|l|}{ RD } & \multicolumn{2}{|c|}{$\begin{array}{l}\text { Corneal oedema } \\
\text { or corneal } \\
\text { leucoma }\end{array}$} & \multicolumn{2}{|c|}{ Cataract } & \multirow[b]{2}{*}{ Strabismus } & \multirow[b]{2}{*}{ Nystagmus } & \multirow{2}{*}{$\begin{array}{l}\text { VA at final } \\
\text { follow up }\end{array}$} \\
\hline & & & & & Pre-op & Post-op & Pre-op & Post-op & Pre-op & Post-op & Pre-op & Post-op & & & \\
\hline 1 & 1 & OD & MGS+anterior PHPV & Lensectomy & & & & & & & + & Resolved & & & \\
\hline 2 & 2 & OD & MGS+PHPV & Lensectomy & + & Resolved & & & + & Remained & & & & & \\
\hline 3 & & OS & MGS+PHPV & $\begin{array}{l}\text { 1. Lensectomy } \\
\text { 2. Coreplasty ( } 5 \text { months later) }\end{array}$ & & & & & & & + & $\begin{array}{l}\text { Resolved } \\
\text { prephthisical }\end{array}$ & & & \\
\hline 4 & 3 & OD & MGS+PHPV & Stable, observe & & & & & & & & & & & \\
\hline 5 & 4 & OS & MGS+PHPV & Stable, observe & & & & & & & & & & & $\mathrm{FC} / 50 \mathrm{~cm}$ \\
\hline 6 & 5 & $\mathrm{OD}$ & MGS+PHPV & $\begin{array}{l}\text { 1. Lensectomy+vitrectomy+silicone oil } \\
\text { 2. Silicone oil removal ( } 6 \text { months } \\
\text { later) }\end{array}$ & + & Resolved & + & Attached & + & Remained & + & Resolved & & & \\
\hline 7 & 6 & OS & MGS+PHPV & Lensectomy & + & Resolved & & & + & Remained & + & Resolved & & & \\
\hline 8 & 7 & OD & MGS+PHPV & Lensectomy & + & Resolved & + & & + & Resolved & + & Resolved & & & \\
\hline 9 & 8 & OS & MGS+PHPV & Observe & & & + & & & & & & + & & \\
\hline 10 & 9 & OD & MGS+PHPV & Stable, observe & & & & & & & & & + & + & \\
\hline 11 & & OS & MGS+PHPV & Lensectomy+vitrectomy $+C_{3} F_{8}$ & & & + & Attached & & & & & & + & \\
\hline 12 & 10 & $\mathrm{OD}$ & MGS+PHPV & Stable, observe & & & & & & & & & + & & \\
\hline 13 & 11 & OS & MGS+PHPV & Lensectomy & + & Resolved & & & + & Remained & & & & & LP \\
\hline 14 & 12 & $\mathrm{OD}$ & MGS+PHPV & Observe & & & + & & & & & & & & \\
\hline 15 & & OS & MGS+PHPV & Observe & & & & & & & + & & & & \\
\hline 16 & 13 & $\mathrm{OD}$ & MGS+PHPV, MGS(fellow eye) & Observe & + & Alleviated & & & & & & & & & \\
\hline 17 & 14 & OS & MGS+PHPV+microphthalmia & Lensectomy & & & + & & & & + & Resolved & & & \\
\hline 18 & 15 & OS & MGS+PHPV+microphthalmia & Stable, observe & & & & & & & & & & & \\
\hline 19 & 16 & OD & MGS+PHPV+microphthalmia & Observe & & & + & & & & + & & & & \\
\hline 20 & 17 & OS & MGS+PHPV+microphthalmia & Lensectomy & + & Resolved & & & + & Resolved & + & Resolved & & & \\
\hline 21 & 18 & OS & MGS+PHPV+microphthalmia & Lensectomy+vitrectomy $+C_{3} F_{8}$ & & & + & Attached & + & Remained & + & Resolved & & & \\
\hline 22 & 19 & OS & $\begin{array}{l}\text { MGS+PHPV+microphthalmia, } \\
\text { MGSs (fellow eye) }\end{array}$ & $\begin{array}{l}\text { 1. Lensectomy } \\
\text { 2. Coreplasty ( } 20 \text { months later) }\end{array}$ & + & Resolved & & & + & Remained & & & & & \\
\hline
\end{tabular}

MGS, morning glory syndrome; OD, right eye; OS, left eye; PHPV, persistent hyperplastic primary vitreous; post-op, postoperatively; pre-op, preoperatively; RD, retinal detachment; VA, visual acuity. 
Three eyes underwent combined vitrectomy and lensectomy, including two eyes with $\mathrm{C}_{3} \mathrm{~F}_{8}$ tamponade and one eye with silicone oil tamponade. In eye 11, partial retinal detachment was noticed around the MGS optic disc with the PHPV cord arising from the disc. No obvious breaks were found. $\mathrm{C}_{3} \mathrm{~F}_{8}$ was injected after the procedure. In eye 21 , a prolonged ciliary process was observed. Retrolental fibrous membrane was removed during surgery. Laser treatment was performed to seal the peripheral iatrogenic hole and $\mathrm{C}_{3} \mathrm{~F}_{8}$ was injected. Eye 6 presented with the PHPV cord arising from the typical MGS optic nerve, a prolonged ciliary process, and anterior proliferative vitreoretinopathy on the $360^{\circ}$ peripheral retina. No obvious breaks were found. Additional $360^{\circ}$ retinotomy was performed followed by laser treatment posterior to the retinotomy edge. Silicone oil was injected after liquid gas exchange.

Three eyes without any complications and two eyes with only strabismus and/or nystagmus were untreated. Five eyes had various complications but unlikely to benefit from surgery. These patients did not have surgery. One of these eyes was given $2 \%$ carteolol hydrochloride and $1 \%$ brinzolamide eye drops to lower the intraocular pressure (IOP).

Eight eyes had secondary glaucoma. This was assessed by either tonometry in older patients or finger palpation in younger patients in combination with the presence of cornea oedema and the disappearance of the anterior chamber. Glaucoma was resolved in seven eyes after lensectomy (including one eye with combined lensectomy and vitrectomy), while the other eye was given medications to lower the IOP. Corneal leucoma remained in six eyes, while the corneal oedema in two eyes resolved after lensectomy. The retina was reattached in three patients who underwent combined lensectomy and vitrectomy. In two eyes which developed pupillary membrane, one eye showed signs of prephthisical changes during follow-up.

\section{DISCUSSION}

In this study, we showed that 22 out of 85 eyes with MGS were associated with PHPV in young patients. This is likely the largest series of such cases reported so far. The symptoms related to PHPV made the age of the patient at the first diagnosis younger than MGS alone. The initial clinical manifestations of MGS with PHPV were mainly leucocoria (8/22) and microphthalmia (6/22). Strabismus was observed in only three eyes in our study compared with $90 \%$ in MGS alone as reported in other studies. ${ }^{20-22}$ Complications such as cataract, glaucoma and retinal detachment were also observed in simple MGS. However, the manifestation of such conditions appeared to be more frequent and severe in MGS combined with PHPV. Facial and central nervous system abnormalities which are known to be associated with MGS were also reported in some of our patients.

The embryogenesis of MGS is poorly understood. ${ }^{23}$ Some have proposed that MGS results from the abnormal closure of the embryonic fissure. ${ }^{24} 25$ More recent studies have suggested that MGS is a primary mesenchymal abnormality resulting in faulty closure of the posterior scleral wall and the poor development of the lamina cribrosa. ${ }^{26}$ Our report shows the relatively high incidence of MGS associated with PHPV, suggesting that the regression of the hyaloidal vasculature is easily compromised in the presence of optic disc defects, which lead to the development of MGS. Our study also supports the hypothesis that the mass of whitish tissue on the abnormal MGS disc is derived from the primitive hyaloid system. ${ }^{27}$ PHPV may be a fundamental condition in MGS and may present in variant forms, including anterior PHPV, PHPV, posterior PHPV or whitish glial tissue only (which may be a type of posterior PHPV).
The association of MGS and PHPV may also have a genetic basis. One possible candidate gene is PAX6. PAX6 is involved in ocular morphogenesis and is expressed in the developing central nervous system and numerous ocular tissues during development (summarised in the Human PAX6 Mutation Database). PAX6 mutations have also been identified in patients with optic nerve malformations, including coloboma, MGS, optic nerve hypoplasia/aplasia and $\mathrm{PHPV}^{28}$ Most cases of PHPV are sporadic. However, it can also be inherited as an autosomaldominant or recessive trait. ${ }^{29-33}$ One study showed that the ocular abnormalities of some Pax $6^{\text {Leca } 4 /+}$ mice were similar to those present in human Peters' anomaly and PHPV. ${ }^{34}$ The relatively high incidence of MGS with PHPV in our study implicates that there may be a genetic link between these two pathologies which needs further study.

In the choice of treatment, we found that lensectomy early on was effective in preventing the progression of corneal opacity in cases with secondary glaucoma and shallow anterior chamber. However, corneal leucoma can rarely be reversed by lensectomy. Vitrectomy was performed if retinal reattachment was anticipated. One should be careful in using silicone oil as it may enter the subarachnoid cavity via subtle holes in the peripapillary area of the retina. ${ }^{35}$ The outcome of surgery was satisfactory in 11 out of 12 eyes. One eye turned to a prephthisical state, possibly due to the formation of fibrous ciliary membrane.

The limitations of this study include its retrospective design and selection bias resulting from the referral setting. Because the percentage association found in this study cannot be generalised given the sampling bias detailed above, we cannot determine the exact prevalence of MGS associated with PHPV. A genetic analysis is beyond the scope of this paper, however it should be performed in a future study to better understand the potential relationship between MGS and PHPV.

In conclusion, our study showed that a significant number of MGS cases were associated with PHPV, suggesting a possible genetic link between these two conditions. Patients with MGS and PHPV showed complications of both diseases, however they were often more severe and manifested at a younger age. Close follow-up was necessary and surgery including lensectomy and vitrectomy were beneficial in the management of complications.

Contributors Each author has participated in this work and can take public responsibility for appropriate portions of the content. The authors all made substantial contributions, including conception and design, data acquisition, analysis and interpretation. All authors approved the final submitted version of this article.

Funding This research was supported by the National Natural Science Foundation Project of China (81070760, 81271045), Project of Shanghai Municipal Level for Emerging Cutting-edge Technology (SHDC12010107).

Competing interests None.

\section{Patient consent Obtained.}

Ethics approval Ethics Committee of Xinhua Hospital, affiliated to Shanghai Jiaotong University School of Medicine, Shanghai, China.

Provenance and peer review Not commissioned; externally peer reviewed.

Open Access This is an Open Access article distributed in accordance with the Creative Commons Attribution Non Commercial (CC BY-NC 3.0) license, which permits others to distribute, remix, adapt, build upon this work non-commercially, and license their derivative works on different terms, provided the original work is properly cited and the use is non-commercial. See: http://creativecommons.org/ licenses/by-nc/3.0/

\section{REFERENCES}

1 Kindler P. Morning glory syndrome: unusual congenital optic disk anomaly. Am J Ophthalmol 1970;69:376-84.

2 Reese $A B$. Persistent hyperplastic primary vitreous. Am J Ophthalmol 1955:40:317-31. 
3 Goldberg MF. Persistent fetal vasculature (PFV): an integrated interpretation of signs and symptoms associated with persistent hyperplastic primary vitreous (PHPV). LIV Edward Jackson Memorial Lecture. Am J Ophthalmol 1997;124:587-626.

4 Cao XG, Li XX, Bao YZ. Morning glory syndrome associated with posterior lenticonus. Open Neurol J 2009:3:45-7.

5 Caprioli J, Lesser RL. Basal encephalocele and morning glory syndrome. Br J Ophthalmol 1983;67:349-51.

6 Holmstrom G, Taylor D. Capillary haemangiomas in association with morning glory disc anomaly. Acta Ophthalmol Scand 1998;76:613-6.

7 Itakura T, Miyamoto K, Uematsu Y, et al. Bilateral morning glory syndrome associated with sphenoid encephalocele. Case report. J Neurosurg 1992;77:949-51.

8 Leitch RJ, Winter RM. Midline craniofacial defects and morning glory disc anomaly. A distinct clinical entity. Acta Ophthalmol Scand Supp/ 1996;(219):16-9.

9 Lenhart PD, Lambert SR, Newman NJ, et al. Intracranial vascular anomalies in patients with morning glory disk anomaly. Am J Ophthalmol 2006;142:644-50.

10 Minotto I, Abdala N, Miachon AA, et al. Basal encephalocele associated with morning glory syndrome: case report. Arq Neuropsiquiatr 2007;65:988-91.

11 Papageorgiou E, Schiefer U, Warmuth-Metz M, et al. Morning glory disc anomaly and frontonasal dysplasia. Ophthalmologe 2007;104:709-12.

12 Razeghinejad MR, Masoumpour M. Chiari type capital I, Ukrainian malformation associated with morning glory disc anomaly. J Neuroophthalmol 2006;26:279-81.

13 Traboulsi El, Jurdi-Nuwayhid F, Torbey NS, et al. Aniridia, atypical iris defects, optic pit and the morning glory disc anomaly in a family. Ophthalmic Paediatr Genet 1986;7:131-5.

14 Cennamo G, Liguori G, Pezone A, et al. Morning glory syndrome associated with marked persistent hyperplastic primary vitreous and lens colobomas. $\mathrm{Br} J$ Ophthalmol 1989;73:684-6.

15 Beyer WB, Quencer RM, Osher RH. Morning glory syndrome. A functional analysis including fluorescein angiography, ultrasonography, and computerized tomography. Ophthalmology 1982;89:1362-7.

16 Manschot WA. Morning glory syndrome: a histopathological study. Br J Ophthalmol 1990;74:56-8

17 Brown GC, Gonder J, Levin A. Persistence of the primary vitreous in association with the morning glory disc anomaly. J Pediatr Ophthalmol Strabismus 1984;21:5-7.

18 Bardakjian T, Weiss A, Schneider AS. Anophthalmia/microphthalmia overview. In: Pagon RA, Adam MP, Bird TD, et al., eds. GeneReviewsTM. Seattle, WA: University of Washington, 1993-2013.

19 Warburg M. Classification of microphthalmos and coloboma. J Med Genet 1993;30:664-9.
20 Harasymowycz P, Chevrette L, Decarie JC, et al. Morning glory syndrome: clinical, computerized tomographic, and ultrasonographic findings. J Pediatr Ophthalmol Strabismus 2005:42:290-5

21 Kim MR, Park SE, Oh SY. Clinical feature analysis of congenital optic nerve abnormalities. Jpn J Ophthalmol 2006:50:250-5.

22 Lee BJ, Traboulsi El. Update on the morning glory disc anomaly. Ophthalmic Genet 2008:29:47-52

23 Golnik KC. Cavitary anomalies of the optic disc: neurologic significance. Curr Neurol Neurosci Rep 2008;8:409-13.

24 Gardner TW, Zaparackas ZG, Naidich TP. Congenital optic nerve colobomas: CT demonstration. J Comput Assist Tomogr 1984;8:95-102.

25 Mafee MF, Jampol LM, Langer BG, et al. Computed tomography of optic nerve colobomas, morning glory anomaly, and colobomatous cyst. Radiol Clin North Am 1987:25:693-9.

26 Pollock S. The morning glory disc anomaly: contractile movement, classification, and embryogenesis. Doc Ophthalmol 1987:65:439-60.

27 Cogan DG. Coloboma of optic nerve with overlay of peripapillary retina. $\mathrm{Br} J$ Ophthalmol 1978:62:347-50.

28 Azuma N, Yamaguchi Y, Handa H, et al. Mutations of the PAX6 gene detected in patients with a variety of optic-nerve malformations. Am J Hum Genet 2003:72:1565-70.

29 Galal AH, Kotoury Al, Azzab AA. Bilateral persistent hyperplastic primary vitreous: an Egyptian family supporting a rare autosomal dominant inheritance. Genet Couns 2006;17:441-7.

30 Khaliq $\mathrm{S}$, Hameed $\mathrm{A}$, Ismail $\mathrm{M}$, et al. Locus for autosomal recessive nonsyndromic persistent hyperplastic primary vitreous. Invest Ophthalmol Vis Sci 2001:42:2225-8

31 Lin AE, Biglan AW, Garver KL. Persistent hyperplastic primary vitreous with vertical transmission. Ophthalmic Paediatr Genet 1990;11:121-2.

32 Sims KB. NDP-related retinopathies. In: Pagon RA, Adam MP, Bird TD, eds. GeneReviews'TM. Seattle, WA: University of Washington, 1993.

33 Prasov L, Masud T, Khaliq S, et al. ATOH7 mutations cause autosomal recessive persistent hyperplasia of the primary vitreous. Hum $\mathrm{Mol}$ Genet 2012:21:3681-94.

34 Ramaesh T, Williams SE, Paul C, et al. Histopathological characterisation of effects of the mouse Pax6(Leca4) missense mutation on eye development. Exp Eye Res 2009;89:263-73

35 Chang S, Haik BG, Ellsworth RM, et al. Treatment of total retinal detachment in morning glory syndrome. Am J Ophthalmol 1984;97:596-600. 